\title{
Leadership Style and Staff Retention in Organisations
}

\author{
Bernard Muhangi Wakabi \\ Mountains of the Moon University, School of Business and Management studies, P. O. Box 837, Fort Portal, Uganda
}

\begin{abstract}
Organisations in all sectors are operating in highly competitive environment which requires that these institutions retain their core employees in order to gain and retain competitive advantage. Because of globalisation and new methods of management, different organisations have experienced competition both locally and globally in terms of market and staff. The role of leaders in employee retention is critical since their leadership styles impact directly on the employees' feelings about the organization. The paper sought to find out the influence of leadership style on staff retention in organisations. The study was purely based on literature review. From the review of several empirical studies it was established that leadership style significantly influences intention to leave of staff and hence there is need to embrace a leadership style that promotes staff retention.
\end{abstract}

Keywords: Leadership, Leadership style, Staff retention, Organisations

\section{Introduction}

Employee retention is one of the most critical issues facing managers in organisations as a result of the shortage of skilled manpower, economic growth and high employee turnover [1]. Whereas it is imperative for organisations, through the employment process, to attract and retain quality employees to the organization, it is more important for managers to device strategies with which to retain the talented employees in the service. Retaining quality staff is important for purposes of keeping loyal customers as well as avoiding the costs of replacing the staff. In the current competitive environment the leaders have to steer their organisations in the competitive business environment [2]. They will handle the challenge if they value employees as assets and as the ones to give their organisations the competitive advantage. This competitive advantage will be guaranteed if the core employees are retained for as long as possible so that continuity of good performance is assured. This paper looks at the relationship between leadership style and staff retention in organisations.

\subsection{Employee retention}

The concept of employee retention emerged with regularity in 1970's and early 1980's because prior to this, most people entered into organisations and remained for a very long time, sometimes for the duration of their working life. But as job mobility and voluntary job changes begun to increase dramatically, employers found themselves with the problem of employee turnover and a matching management tool known as employee retention begun to be developed [3].

Retention is a voluntary move by an organisation to create an environment which engages employees for long term [1]. Retention of human resources refers to the attempts to ensure that employees stay in the organization and that voluntary turnover is minimized. The main purpose of retention is to prevent competent employees from leaving the organisation as this could have adverse effects on productivity and service delivery [4]. The author in [1] contends that retention allows senior and line managers to attract and effectively retain critical skills and high performing employees. The objective of retention policies should be to identify and retain committed employees for as long as is mutually profitable to the organisation and the employee [5].

\subsection{Leadership and Leadership Style}

Leadership has many definitions but no real consensus; essentially it is a relationship through which one person influences the behavior or actions of other people. In everyday speech leadership and Management are erroneously used interchangeably. Management is about developing, planning and controlling of organizational resources while leadership is about the aligning of people to the expected outcomes of organisational vision. In order to lead, one must be able to manage and hence the two are closely related [6]. According to [7], leadership is a process of encouraging and helping others to do something of their own volition, neither because it is required nor because of the fear of consequences of non-compliance. Leadership is thus a process of encouraging and helping others to work enthusiastically towards objectives. It is the human factor that binds a group together and motivates it towards goals transforming the group's potentials into reality. A capable leader provides direction for the organisation and leads followers towards achieving desired goals [8].

Leaders use their influence factor to draw people towards achieving goals and to maximize the results in the organization. The influence factor does not mean the leader having power over the followers and controlling or directing them to the goals the leaders want to achieve; rather it is the leaders' own actions that affect the follower's behavior and actions. Generally, followers will emulate the leader's acts and behaviours thus leading to the achievement of the desired goals [9]. This implies that leaders must not only inspire their subordinates through words but also calculated actions. 


\section{International Journal of Science and Research (IJSR) \\ ISSN (Online): 2319-7064}

Index Copernicus Value (2013): 6.14 | Impact Factor (2014): 5.611

\subsection{Problem Statement}

Managers in organizations adopt different leadership styles depending on their orientation. The manager's orientation may be influenced by culture, education system that the manager went through, or the organisational environment. Any leadership style adopted by a particular manager has a way it impacts on staff motivation, performance and organisational commitment; which in turn may influence employees' decision either to leave or stay with the organisation. Retaining employees is important to the continuing success of any organisation, because of the skills and knowledge that employees accumulate while working for the organisation. An organisation with a high level of employee turnover faces the costs and effort of recruiting, inducting and training new employees, with the risk of business disruption while new employees get up to speed on the job. Whereas a majority of observers have attributed labour turn over in organisations to all sorts of motivational factors, an understanding of the contribution of leadership style needs to be put into context. This paper seeks to explore empirical studies so far made on leadership style and employee turnover and retention in order to come up with the dominant views about the topic.

\subsection{Research Question}

What is the relationship between leadership style and staff retention in organizations?

\subsection{Theoretical overview}

\section{a. McGregor's theory $X$ and $Y$}

Douglas McGregor's famous distinction between Theory $\mathrm{X}$ and Theory Y brings out well the two extreme styles of management; task-oriented and relationship-oriented management styles as advanced in the behavioral theory (explained below). In his 1960 book, "The Human Side of Enterprise" (McGraw-Hill), McGregor made a powerful observation that managerial practice often expresses some very deep assumptions about the nature of human beings: Two competing theories about human nature, he claimed, dominate the managerial thought-world.

Theory X says that the average human being is lazy and self-centred, lacks ambition, dislikes change, and longs to be told what to do. The corresponding managerial approach emphasizes total control. Employee motivation, it says, is all about the fear and the pain. Theory $\mathrm{X}$ is criticized for its negative view about people and for its autocratic approach in enforcing organisational standards [8]. Theory $\mathrm{Y}$ maintains that human beings are active rather than passive shapers of themselves and of their environment. They long to grow and assume responsibility. The best way to manage them, then, is to manage as little as possible. Give them water and let them bloom, say the Ytypes. Theory Y corresponds with relationship oriented management style. One would assume that adoption of theory $\mathrm{Y}$ would help employee retention; however, other behavioral theories (as explained below) will tell us that it is not always the case.

\section{b. McClelland's achievement theory}

Later, David McClelland gave a contribution in his 1961 book, "The achieving society". $\mathrm{He}$ identified three motivators that he believed we all have: a need for achievement, a need for affiliation, and a need for power. People will have different characteristics depending on their dominant motivator. According to McClelland, these motivators are learned (which is why this theory is sometimes called the Learned Needs Theory). McClelland says that, regardless of our gender, culture, or age, we all have three motivating drivers, and one of these will be our dominant motivating driver. This dominant motivator is largely dependent on our culture and life experiences. According to McClelland, workers whose dominant motivator is achievement have strong need to set and accomplish challenging goals, take calculated risks, like to receive regular feedback on their achievement and progress and like to work alone. Conversely, those whose dominant motivator is affiliation want to belong to a group, be liked and favour collaboration over competition. The workers whose dominant motivator is power will invariably want to control others, like to win arguments, enjoy competition and winning, and enjoy status and recognition. The challenge for managers therefore is to understand employees' dominant motivator in order to be able to motivate them accordingly. With motivation guaranteed, the task to retain an employee in the organization becomes a bit easier.

\section{c. The Behavioral Theory}

The behavioral theory assumes that leaders can be made rather than born and that leadership is based on definable and learnable behavior. Behavioral theories of leadership do not seek in-born traits or capabilities but rather they look at what leaders actually do. Unlike the trait theory, the behavioral theory assumes that leadership capability can be learned rather than being inherent. The theory identifies two behaviors that leaders may exhibit; the task-oriented behavior and relationship-oriented behavior. In modern times, relationship-oriented behavior seems to be the preferred style.

\section{Methodology}

This article is based purely on literature review. It adopts an exploratory design trying to establish what is available in the literature concerning leadership styles and staff retention and turn-over. There is sufficient literature on leadership styles and staff turn-over and less about leadership style and retention. This paper is meant to establish the dominant views from empirical studies about how leadership styles influence employees' decisions to stay or leave the organization.

\section{Findings and Discussion}

Style of Leadership is the first issue which is focused on when a leader's performance is assessed by others. It is also one of the most popular topics among the researchers in the leadership area. Several studies have tried to explain the different styles of leadership and the extent to which leaders' style can affect the overall success of a team or an 


\section{International Journal of Science and Research (IJSR) \\ ISSN (Online): 2319-7064}

Index Copernicus Value (2013): 6.14 | Impact Factor (2014): 5.611

organisation being led by them. In addition, so many studies have tried to explain the relationship between managers' leadership styles and the different aspects of employees' organizational behaviors. Job satisfaction, job performance and turnover and retention are some of the most important areas in organisational behavior [10].

\subsection{Leadership Style}

Author in [11] defined leadership style as "the way in which the functions of leadership are carried out and the manner that a manager chooses to behave towards employees. Different theories of leadership have introduced several styles of leadership. Nevertheless, the paper focuses on behavioral studies and the leadership styles introduced by these studies. Leadership style is a behaviorally oriented approach to understanding the concept of leadership. Subordinates, normally look at their leaders' behavior as their style of leadership. From this viewpoint, author in [12] concluded that "behavior approach" and "style approach" could be used interchangeably. The style approach focuses on leaders' behaviors and explains how they combine task and relationship behaviors to influence subordinates in their efforts to reach an organisational goal [13]. Several behavioral studies have pointed to two leadership styles; the task-oriented and the relationship-oriented leadership styles.

\subsection{Task-oriented leadership behaviors}

The primary concern of task-oriented leaders is achieving defined targets of their organisation. Author in [13] argued that task-oriented leaders encourage their employees to achieve their objectives by giving them exact definitions about their roles, establishing objectives and criteria of evaluation, specifying directions and instructions, setting time schedules, and determining the ways by which goals could be achieved. He believed that task-oriented leaders often apply a one-way method to communicate with subordinates about their duties and responsibilities and the way they are expected to fulfill their tasks. Authors in [14] specified some activities such as clarifying responsibilities and roles, defining objectives, performance measurement \& control, and planning for short-term periods as the main behaviors of task-oriented leaders. What is there to understand therefore is how the task oriented behaviors relate with motivation of staff and intentions to stay in or leave the organisation. Defining roles and specifying directions for staff may be a motivator for staff depending on what kind staff one is dealing with and may as well be a "demotivator" for others. Basing on McClelland's achievement theory, it may all depend on the characteristics of a particular employee.

\subsection{Relationship-oriented leadership behaviors}

The main concern of relationship-oriented leaders is mostly focused on building and developing interpersonal relationships. Author in [13] argued that unlike taskoriented leaders, relationship-oriented leaders prefer a twoway method to communicate with their subordinates. He believed that "this is because of their desire to support their employees socially and emotionally". According to him, it is also very important to them to help employees to feel comfortable in the workplace and develop their careers. According to author in [14], the most important behaviors of relationship-oriented leaders could be categorized into three sorts of behaviors including "supporting", "developing", and "recognizing" behaviors. Still the success of relationshiporiented leadership style will depend on the characteristics of a particular employee. For instance if the employee happens to fall in the category as described by McGregor in theory X, then relationship oriented style will not be helpful.

\subsection{Employee turnover/retention}

Employee turnover is one of the most frequently studied phenomena in the area of human resource management [15]. Authors in [16] define employee turnover as the rotation of employees around job positions available in the labour market. According to them, this rotation could result in a transfer between organizations, a change in the job position and occupation or sometimes a shift between two states of employment and unemployment.

There are different reasons why people move from an organisation to another. Authors in [17] believe that job stress and the wide range of stressors, low level of organisational commitment, and job dissatisfaction are the most common reasons which are expressed by employees as a reason for leaving their jobs. It should be noted here that the leadership style of a manager may be among (if not the main) stressors. A manager is the first reflection of the organization in the eyes of the employees.

Authors in [18] introduce economic reasons as the main reason why employees decide to leave their jobs. While author in [19] believes that there is a strong link between the rate of unemployment and the level of job satisfaction. He argues that job stress also can result in employee turnover. In addition, ambiguity in roles and responsibilities causes a situation of uncertainty which normally leads to job stress and finally turnover. Misunderstanding about what is expected by the workplace, and the way in which those expectations should be met could be regarded as an important reason of role ambiguity and consequently employee turnover [20]. If roles and responsibilities are not clearly defined by the manager or leader, the rate of employee turnover will get accelerated considerably [21].

Quantitative approach to the management of human resources is another important factor which results in the disenchantment of employees and consequently leads to employee turnover [21]. Hence, the author believes that managers should avoid using a quantitative approach to managing their subordinates. Looking at it closely quantitative approach is likely to be applied by the task oriented leader. Also, cost-oriented approach toward employment of human resources can increase employee turnover. This approach should be avoided if the management of a company intends to avoid employee turnover and enhance the company's competitive position in the market [22]. Authors in [23] point out that salary and its related variables have a modest effect on turnover. 


\section{International Journal of Science and Research (IJSR) \\ ISSN (Online): 2319-7064}

Index Copernicus Value (2013): 6.14 | Impact Factor (2014): 5.611

Their study looks for a relationship between salary, employee performance and turnover. They conclude that if good performers are not rewarded sufficiently, they easily leave their jobs. There are also some other factors to blame such as poor employment practices, style of management, lack of a mechanism for recognition, lack of competitive rewarding system and toxic environment in the workplace [16].

A range of managerial practices and policies have also been found to be effective at reducing turnover, including fostering open communication, building trust, enriching jobs, promoting fairness, instilling identification with the organisation and supporting family life [24], [23].

\subsection{Costs of staff turnover}

It is evident that employee turnover is a costly phenomenon for organisations and should be avoided where possible and practical. These costs include the expenses of recruitment and training [5], decline in productivity, and lost time [25]. This argument clearly shows that employee turnover affects the overall performance of the organization and if the management neglects to manage it properly, a negative effect on the performance will be unavoidable. Clearly, it can be seen that voluntary turnover imposes significant costs on organisations, both in terms of direct costs (replacement, hiring and selection process, expenses of temporary staff, and the wasted time), and more significantly, in terms of indirect costs (decline in staff's morale, extra pressure on remaining employees, decline in the quality of product/service, costs of learning, and the lost knowledge from the organization) [28]. Staff retention should therefore be every managers concern at all times if smooth operations of organisations is to be attained and sustained.

\subsection{Role of Leadership Style on Staff Retention}

One of the critical roles of management is to create a work environment that will endear the organization to employees. It also includes influencing these employees' decision to be committed and remain with the organization even when other job opportunities exist outside the organization [1]. Author in [29] observes that the role of leadership and a supervisor is crucial in staff retention, and argues that employees leave managers not companies.

According to [30], organizations can no longer afford to leave the responsibility for keeping well performing employees in the hands of the Human Resource Departments. Responsibility and accountability for retaining talent need to move out to the front lines and into the hands of leaders. Leaders and their skill in building a climate of retention, a culture that speaks to employees in a way that encourages them to stay, will be an organization's best defense against unwanted turnover. Leaders are therefore the secret weapon in keeping valued talent longer. A two way communication is regarded as a core management competency and a key management responsibility. Leaders should adopt a style that would establish and confirm their leadership authority by means of appearing competent and trustworthy. Effective leaders should guide members in a manner that allows them to contribute to the achievement of the group's overall goal [9].

Authors in [2] argue that employees are more likely to remain with an organization if they belief that their managers show interest and concern for them, if they know what is expected of them, if they are given a role that fits their capabilities and if they receive regular positive feedback and recognition. The quality of relationship an employee has with his or her immediate managers elongates employee stay in an organization [31] cited in [1]. Author in [6] affirms that incompetent leadership results in poor employee performance, high stress, low job commitment, low job satisfaction and turnover intent. Research conducted on the state of South African Training industry indicated that management style was the most prominent retention factor in South Africa [32]. Authors in [33] found in their research that majority of the employees in organizations surveyed planned to remain with their organizations at least for the next five years because of the prevailing culture of management care. Author [34] observed that leadership behaviour has a positive influence on organizational commitment and turnover intention. Authors in [35] found that organizational culture and leadership are some of the major causes of staff turnover in the hospitality industry. Authors in [36] contend that transformational leadership (which is comparable to relationship-oriented leadership style) is the key factor in reducing and mitigating turnover intentions. Author in [37] established that leadership style, specifically lack of involvement in decision making and inadequate communication were some of the issues that caused dissatisfaction of academic staff of the University of Nairobi. It is therefore evident in literature that leadership style is crucial in staff retention. Organisations must therefore take extra care while hiring managers; in addition to professional competence, managers must be thoroughly tested for their likely leadership style.

\section{Conclusion}

Based on the findings in the literature, this paper concludes that leadership style influences staff retention in organisations. All the literature reviewed reported an inverse relationship between leadership style and intention to leave. Intention to leave was found to be the preferred measure commonly used in different studies to assess turnover and retention. When leadership style is unfavourable intention to leave increases and when it is favorable intention to leave decreases, hence enhancing staff retention [2]. Leadership style adopted by managers should therefore be given the attention it deserves if organisations are to retain their treasured staff. Organisations should therefore ensure that they pick on managers with the right character traits.

\section{References}

[1] S.O Michael, (2008). Using Motivational Strategy as Panacea for Employee Retention and Turnover in Selected Public and Private Sector Organisations in

\section{Volume 5 Issue 1 January 2016}




\section{International Journal of Science and Research (IJSR) \\ ISSN (Online): 2319-7064 \\ Index Copernicus Value (2013): 6.14 $\mid$ Impact Factor (2014): 5.611}

the Eastern Cape Province of South Africa, Master of Commerce Thesis, University of Fort Hare. 2008

[2] J.Ng'ethe, "Influence of leadership style on the academic staff retention in public universities in Kenya", International journal of business and social science, 3 No.21, 2012.

[3] J. L. McKeown, Retaining Top Employees, New York: McGraw-Hill, 2002.

[4] W.M. Chiboiwa, M.O.Samuel, J.Chipunza, “An Examination of Employee Retention Strategy in a private Organisation in Zimbabwe", African Journal of Business Management, 4 (10), 2103-2109, 2010.

[5] J.Sutherland, "Job-to-job turnover and job to-nonemployment movement” Personnel Rev. 31(6): 710-721. [44], 2000.

[6] F. Gwavuya, (2011), "Leadership Influences on Turnover Intentions of Academic Staff in Tertiary Institutions in Zimbabwe", Journal of Academic Leadership, 9(1), 2011.

[7] J. A Okumbe, Educational Management: Theory and Practice, Nairobi University Press, 1998.

[8] M.L.Voon et al. "The influence of leadership styles on employees' job satisfaction in public sector organisations in Malaysia", International Journal of Business, Management and Social Sciences, Vol. 2, No. 1,, pp. 24-32, 2011.

[9] J.Mat, The Influence of Leadership Style on Internal Marketing in Retailing, $\mathrm{PhD}$ Thesis, University of Stirling, 2008.

[10] A. Kryvenda, Reducing Adversity of Employee Turnover within Projects. Case Study at Volvo Car Corporation, 2012.

[11] L. J. Mullins, Management and Organisational Behaviour, Pitman Publishers, London, 2000

[12] A. Bryman, Charisma and leadership in organizations, Sage, London, 1992

[13] P. G. Northouse, Leadership: Theory and practice, Thousand Oaks, CA: Sage, 2004

[14] G. Yukl, R. Mahsud, "Why flexible and adaptive leadership is essential", Consulting psychology journal: practice and research, 62,(2) pp81-93, 2010.

[15] J.D Shaw, J. E. Delery, G. D. Jenkins Jr., N. Gupta, "An organization-level analysis of voluntary and involuntary turnover", Academy of Management Journal, 41(5), 511-525, 1998.

[16] S. Abassi, K. Hollman, "Turnover: the real bottom line", Public Personnel Management, S.N, 2000.

[17] L. Firth, D. J . Mello, K. A. Moore, C. Loquet, "How can managers reduce employee intentions to quit?", Journal of managerial psychology,1,pp.170-87, 2004.

[18] T.L.P Tang, J.W Kim, D.S.H Tang, "Does attitude toward money moderate the relationship between intrinsic job satisfaction and voluntary turnover?" Human relations, 53(2), pp213-245, 2000.

[19] C. Trevor, "Interactions among actual ease - of movement determinants and job satisfaction in prediction of voluntary turnover", Acad. Manage J. 44 (6): 621-638, 2001.

[20] P.M Muchinsky, Psychology applied to work: an introduction to industrial and organizational psychology, $3^{\text {rd }}$ ed. Brooks/Cole publishing company, USA, 1990.

[21] H. A. Ongori, "A review of literature on employee turnover", African journal of business and management, pp 49-54, 2007.

[22] A. H.M. Shamsuzzoha, M. R. H. Shumon, "Employee Turnover- a Study of its Causes and Effects to Different Industries in Bangladesh", Manufacturing Engineering/Vyrobne Inzinierstvo, 6(3), 64-68, 2007.

[23] R. W. Griffeth, P. W. Hom, S. Gaertner, "A metaanalysis of antecedents and correlates of employee turnover: update, moderator tests, and research implications for the next millennium", Journal of management, 26(3) pp463-488, 2000.

[24] L. W. Porter, R.W. Steers, "Organisational work and personal factors in employee turnover and absenteeism" Psychological bulletin, Vol. 80 pp151-176, 1973.

[25] C. Gustafson, "staff turnover: Retention". International journal of contemporary Hospitality manage management, 14 (3) pp106-113, 2002.

[26] J. D. Shaw, J. E. Delery, G. D. Jenkins Jr., N. Gupta, "An organization-level analysis of voluntary and involuntary turnover", SN, 1998.

[27] J. Beardwell, T. Claydon, Human Resource Management: A contemporary Approach, Prentice Hall London, 2007.

[28] S. Dibble, Keeping your Valuable Employees: Retention Strategies for your Organisation, John Wiley \& Sons, Inc., Canada, 1999.

[29] J. L. Price, "Reflections on the Determinants of Voluntary Turnover", International Journal of Manpower, 22 (7), 600-624, 2001.

[30] P.E Spector, Job satisfaction: Application, assessment, causes and consequences, Thousand Oaks, CA,Sage Publications, Inc., 1997.

[31] F.G. Netswera, E.M.Rankhumise, T. R. Mavundila, "Employee Retention Factors for South African Higher Education Institutions" A Case Study, SA Journal of Human Resource Management, 3 (2), 36-40, 2005.

[32] M.A Armstrong, Handbook of Human Resource Management Practice, Kogan Page Limited, London, 2010.

[33] J. C. Chew, The Influence of Human Resource Management Practices on the Retention of Core employees of Australian Organisation, $\mathrm{PhD}$ Thesis, Murdoch University, 2004.

[34] F. Muindi, The relationship between Participation in Decison making and Job Satisfaction among academic Staff in the School of Business University of Nairobi, MBA Thesis, University of Nairobi, 2010.

\section{Author Profile}

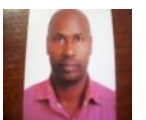

Bernard Muhangi Wakabi is a $\mathrm{PhD}$ student at Uganda Management Institute. He is a lecturer at Mountains of the Moon University in the School of business and Management Studies where he also doubles as the coordinator of Internships and Field placement. Bernard holds a Bachelor of Commerce degree from Makerere University and an MBA from Uganda Martyrs University. 